\title{
High-Speed and Low-Energy Flip-Flop Operation of Asymmetric Active-Multimode Interferometer Bi-Stable Laser Diodes
}

Jiang, Haisong; Chaen, Yutaka; Hagio, Takuma; Tsuruda, Kazuisao; Jizodo, Makoto; Matsuo, Shinji; Xu, Jing; Peucheret, Christophe; Hamamoto, Kiichi

Published in:

Proceedings of the European Conference on Optical Communication (ECOC) 2011

Publication date:

2011

Document Version

Publisher's PDF, also known as Version of record

Link back to DTU Orbit

Citation (APA):

Jiang, H., Chaen, Y., Hagio, T., Tsuruda, K., Jizodo, M., Matsuo, S., Xu, J., Peucheret, C., \& Hamamoto, K. (2011). High-Speed and Low-Energy Flip-Flop Operation of Asymmetric Active-Multimode Interferometer BiStable Laser Diodes. In Proceedings of the European Conference on Optical Communication (ECOC) 2011 (pp. Th.11.LeSaleve). Optical Society of America. http://www.ecoc2011.org/

\section{General rights}

Copyright and moral rights for the publications made accessible in the public portal are retained by the authors and/or other copyright owners and it is a condition of accessing publications that users recognise and abide by the legal requirements associated with these rights.

- Users may download and print one copy of any publication from the public portal for the purpose of private study or research.

- You may not further distribute the material or use it for any profit-making activity or commercial gain

- You may freely distribute the URL identifying the publication in the public portal 


\title{
High-Speed and Low-Energy Flip-Flop Operation of Asymmetric Active-Multimode Interferometer Bi-Stable Laser Diodes
}

\author{
H. Jiang ${ }^{(1)}$, Y. Chaen ${ }^{(1)}$, T. Hagio ${ }^{(1)}$, K. Tsuruda ${ }^{(1)}$, M. Jizodo ${ }^{(1)}$, \\ S. Matsuo ${ }^{(2)}$, J. Xu $^{(3)}$, C. Peucheret ${ }^{(3)}$ and K. Hamamoto ${ }^{(1)}$ \\ ${ }^{(1)}$ Interdisciplinary Graduate School of Engineering Sciences (I-EggS), Kyushu University, \\ 6-1 Kasuga-koen, Kasuga, Fukuoka 816-8580, Japan \\ (2) NTT photonics laboratories, 3-1 Morinosato Wakamiya, Atsugi, Kanagawa 243-0198, Japan \\ ${ }^{(3)}$ DTU Fotonik, Department of Photonics Engineering, Technical University of Denmark, Building 343, DK-2800, Kgs. Lyngby, Denmark \\ Author e-mail address: jiangh7@asem.kyushu-u.ac.jp
}

\begin{abstract}
High-speed (121/25 ps rise/fall time) and low-switching energy (7.1 and $3.4 \mathrm{fJ})$ alloptical flip-flop operation of single-wavelength high-mesa asymmetric active-MMI bi-stable laser diodes is demonstrated for the first time using 25 ps long switching pulses.

OCIS codes: (130.0250) Opto-electronics; (130.4815) Optical switching devices
\end{abstract}

\section{Introduction}

To reduce the huge amount of electrical power consumed at current network routers due to optical-to-electrical-tooptical (OEO) conversion [1], one possible solution is to realize all-optical routers. Optical random access memory (RAM) is a key functionality in such all-optical routers. So far, several optical memory elements have been proposed as all-optical memory [2-9]. Recently, we have demonstrated high-mesa waveguide structure asymmetric active-multimode interferometer bi-stable laser diodes (MMI BLDs) [5]. The implemented devices showed a wide hysteresis window, which is an important feature of future highly integrated RAMs [6], together with superior single-wavelength emission (without using grating structures) [5]. However, in order to establish the full potential of this technology, it is essential to demonstrate high speed operation compatible with multi-gigabit per second signals.

In this work, we demonstrate the high speed response of high-mesa asymmetric active-MMI BLDs for the first time. All-optical flip-flop switching is achieved with 25 ps long pulses. The implemented devices showed fast rise and fall times of $121 \mathrm{ps}$ and $25 \mathrm{ps}$, respectively. Furthermore, the required set and reset pulse energies were only $7.1 \mathrm{fJ}$ and $3.4 \mathrm{fJ}$, respectively.

\section{Concept and Design}

The bi-stability of the active-MMI BLDs is mainly based on cross-gain saturation between two identical propagation paths in the same cavity. Extremely wide hysteresis windows have been realized utilizing the bistability of the lowest two lateral mode paths $\left(0^{\text {th }}\right.$ order mode path, and $1^{\text {st }}$ order mode path $)$ in the asymmetric active-MMI configuration, as shown in Fig. 1 (a) [7-9]. Moreover, we have utilized high-mesa for the waveguide structure which has shown single-wavelengh emission with side mode suppresion ratio (SMSR) of $30 \mathrm{~dB}$ [5]. To further decrease the threshold current, a saturable absorber (SA) region with a length of only $25 \mu \mathrm{m}$ was implemented in the device used in this work. The length portion of the cross-gain saturation region between the two

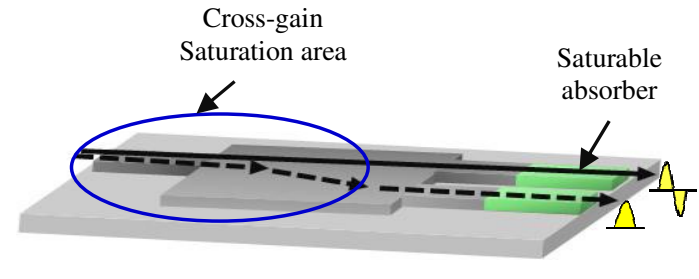

(a)

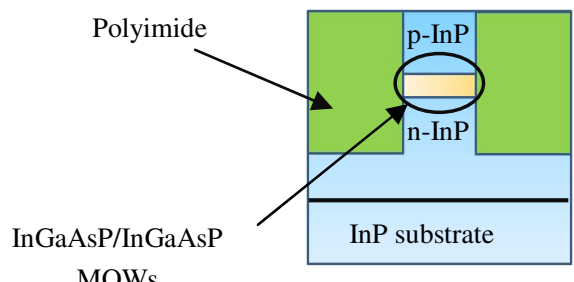

(b)

Fig 1. Schematic view of high-mesa asymmetric active-MMI BLDs. (a) Waveguide configuration, (b) cross-section. 
propagation paths was increased to approximately $80 \%$ to maintain a sufficiently large hysteresis window with such a short saturable absorber design [7].

The implemented asymmetric active-MMI BLDs had a cavity length of $\mathrm{L}=315 \mu \mathrm{m}$ (including $25 \mu \mathrm{m}$ length SA region). The MMI region width and length were $8 \mu \mathrm{m}$ and $138 \mu \mathrm{m}$, respectively. The access waveguide width was set to be $3 \mu \mathrm{m}$. They were realized in high-mesa waveguide structure as shown in Fig. 1 (b). We used InGaAsP/InGaAsP multiple quantum wells $(\lambda=1.55 \mu \mathrm{m})$ as in [5]. The InGaAsP/InGaAsP multiple quantum wells were grown by metal-organic vapor phase epitaxy (MOVPE) on an InP substrate. To realize precisely the designed MMI geometries, an i-line stepper was used for the lithography technique. The structure was etched down using reactive ion etching (RIE) to fabricate the high-mesa waveguide.

\section{Results and discussion}

Fig. 2 (a) shows the power-current (P-I) characteristics of the implemented devices. It can be seen that, a low hysteresis threshold $\mathrm{I}_{\mathrm{th}}$ of $60 \mathrm{~mA}$, and a wide hysteresis window $\Delta \mathrm{I}_{\mathrm{hys}} \%$ (defined as the percentage ratio of the hysteresis window width to the lower hysteresis threshold) of $15 \%$ could be obtained. This was made possible thanks to the increase of the cross-gain region to reach $80 \%$ of the total device length. From this result, it was confirmed that high-mesa waveguide structure asymmetric active-MMI BLDs can achieve sufficiently large hysteresis windows with relatively low threshold current. Fig. 2 (b) shows the emission spectrum in the "on" state. Remarkable single wavelength emission performance, based solely on the active-MMI phenomena, has been successfully obtained at a wavelength of $\lambda=1549 \mathrm{~nm}$, with a side-mode suppression ratio of $25 \mathrm{~dB}$.

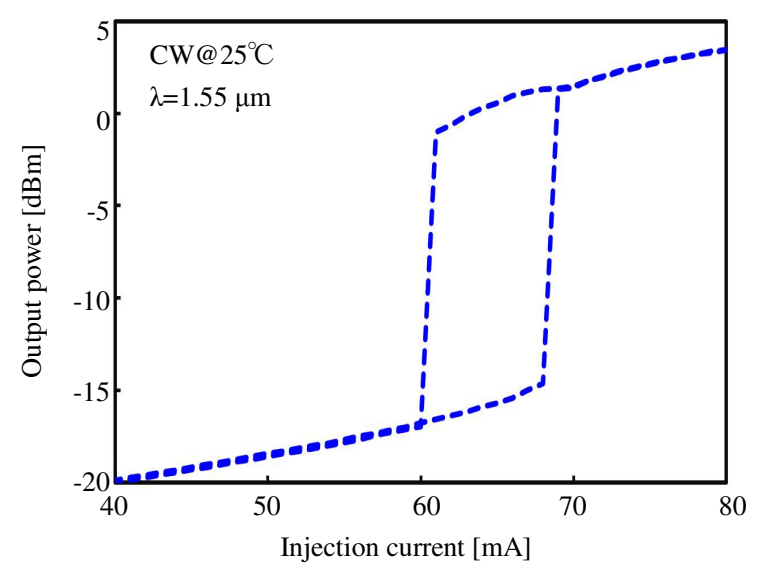

(a)

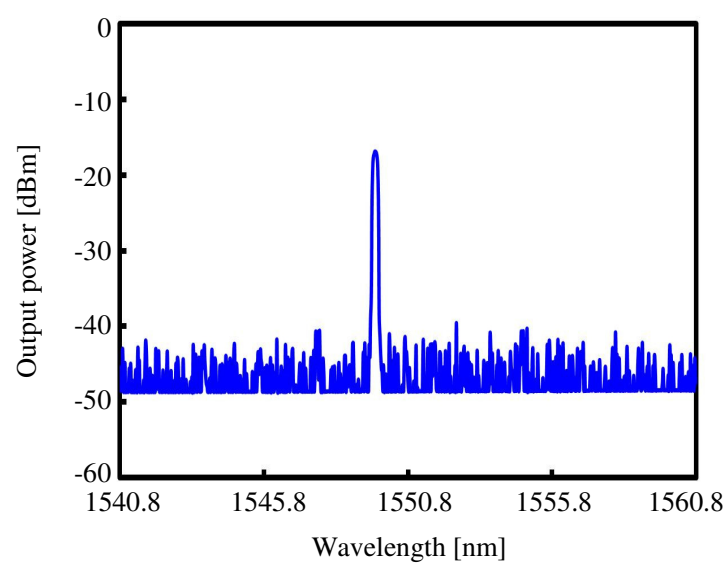

(b)

Fig. 2. Characteristics of the implemented devices. (a) Power-current characteristics and (b) emission spectrum in the "on" state of the implemented devices.

In order to investigate the dynamic memory operation, light pulses at $\lambda=1549 \mathrm{~nm}$, which was the lasing wavelength, were injected for off-to-on switching and light pulses at $\lambda=1554 \mathrm{~nm}$, which was different from lasing wavelength, were used for on-to-off switching. Fig. 3 shows the experimental setup for the measurement of the dynamic behavior of the all-optical flip-flops. The pulses were generated from a $40 \mathrm{Gbit} / \mathrm{s}$ bit-pattern generator and had a duration of $25 \mathrm{ps}$. A fiber delay line was used to introduce a delay between the set and reset pulses. The results are shown in Fig. 4. It can be seen that the high-mesa asymmetric active-MMI BLDs could realize all optical flip-flop switching using 25 ps pulses. Furthermore, the switching energies of the set and reset pulses were only $7.1 \mathrm{fJ}$ and $3.4 \mathrm{fJ}$ respectively. Fast rise and fall times were also recorded for the devices. The evaluated rise and falltimes were 121 ps and 25 ps, respectively (see Fig. 4 (c), and (d)), despite the fact that the devices were carrier injected bi-stable laser diodes.

\section{Conclusion}

We have successfully demonstrated all-optical flip-flop operation of high-mesa asymmetric active-MMI BLDs using $25 \mathrm{ps}$ long pulses. The devices showed very fast rise and fall times of $121 \mathrm{ps}$ and $25 \mathrm{ps}$, respectively, with low 
set and reset pulse energies of $7.1 \mathrm{fJ}$ and $3.4 \mathrm{fJ}$, respectively. We expect the potential of asymmetric active-MMI BLDs can be exploited in future all optical routers.

This work was supported in part by NICT, Japan.

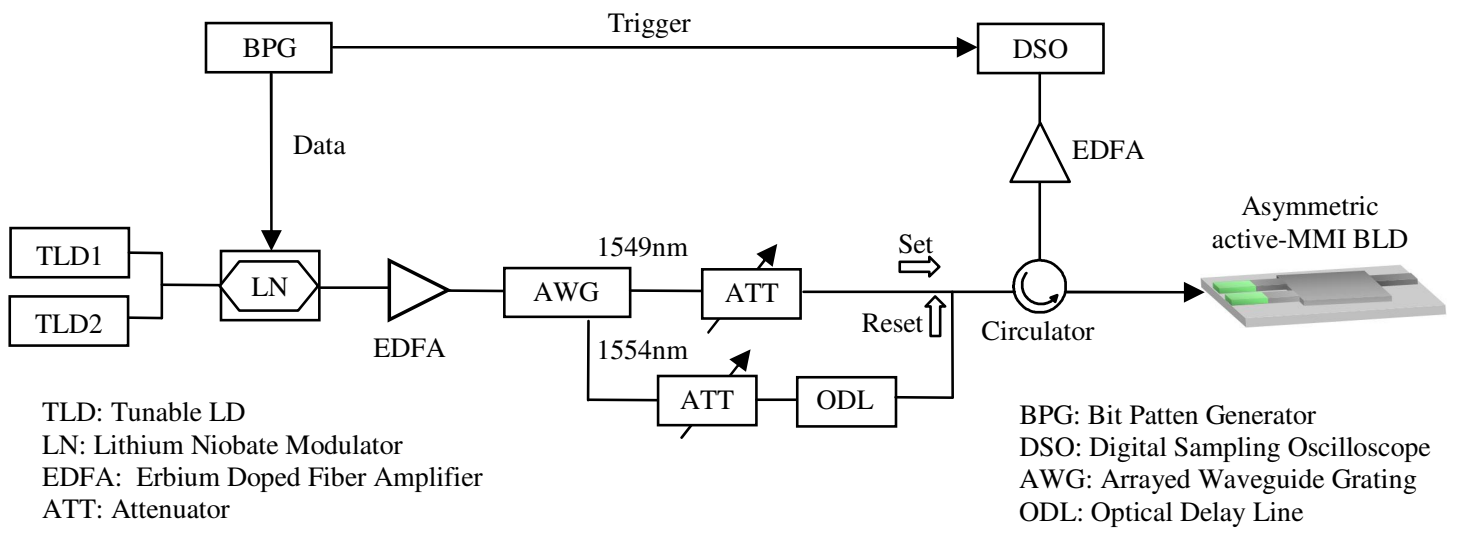

Fig. 3. Experimental setup for the measurement of the dynamic behavior of the all-optical flip-flops.
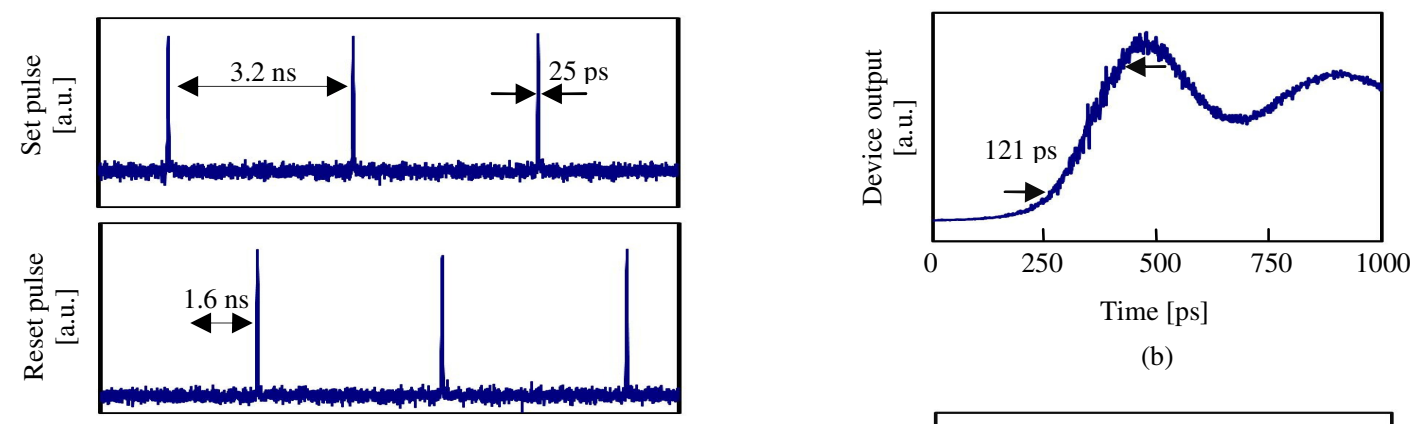

(b)

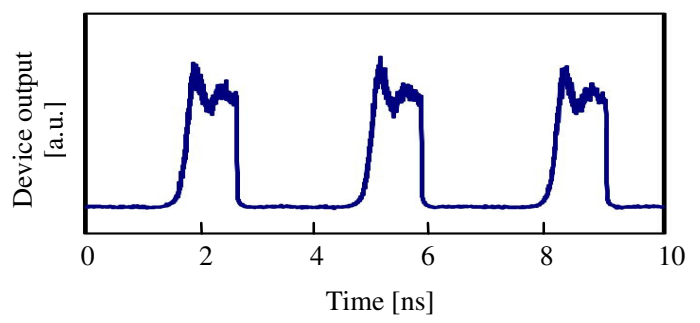

(a)

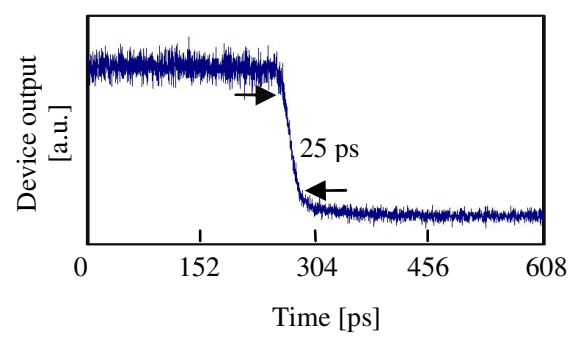

(c)

Fig. 4. Dynamic memory operation of high-mesa asymmetric active-MMI BLDs using 25 ps switching pulses.

(a) Set and reset pulses, as well as device output, (b) rise time and (c) fall time characterisation.

\section{References}

[1] http://www.nistep.go.jp/achiev/ftx/jpn/stfc/stt063j/0606_03_featurearticles/0606fa01/200606_fa01.html.

[2] M. T. Hill et al, Nature 432, pp. 206-209 (2004).

[3] T. Katayama et al, in Proc. LEOS 2008 (Newport Beach, USA), ThG1 (2008).

[4] L. Liu et al, Nature Photon 4, pp. 182-187 (2010).

[5] H. Jiang et al, in Proc. IPRM 2011 (Berlin, Germany), MP-14 (2011).

[6] H. A. Bastawrous et al, in Proc. ECOC2009 (Vienna, Austria), P.2.15 (2009).

[7] H. Jiang et al, in Tech. Dig. MOC 2009 (Tokyo, Japan), G5 (2009).

[8] H. A. Bastawrous et al, in Tech. Dig. OFC 2010 (San Diego, USA), JWA34 (2010).

[9] H. Jiang et al, in Tech. Dig. ISLC 2010 (Kyoto, Japan), P30 (2010). 